\title{
Virtual laboratories in science and engineering
}

\author{
Valdis Priedols, Anita Jansone \\ Liepaja University
}

\section{INTRODUCTION}

Virtual laboratories have been used for several decades as a tool to help in the educational process. However, it is not always clear the purpose and correct way to use this tool. Educators need to improve their work so that the teaching process is more efficient. A wide range of virtual resources is available in different languages. Most of the resources are in English and some in Latvian, therefore the use of virtual laboratories is made very simple.

Hypothesis: The efficient use of a virtual laboratory depends on multiple circumstances.

The concept of the virtual laboratory is understood and used differently by many authors and researchers because that depends on the purpose of use. In the most general terms, a virtual laboratory is a computer-based activity where students interact with an experimental apparatus or other activity via a computer interface. Typical examples is a simulation of an experiment, whereby a student interacts with programmed-in behaviours, and a remote-controlled experiment where a student interacts with real apparatus via a computer link.

This kind of process allows students to explore a topic by comparing and contrasting different scenarios, to pause and restart an application for reflection and note taking, to get practical experimentation experience over the Internet.

The most recognizable are computer simulations that allow us to examine basic concepts in physics. These simulations are broadly used in the teaching and learning process in different ways.

The purpose of this research is to study through virtual laboratories that are broadly used in educational institutions and to examine the usefulness and impact of using such laboratories.

\section{MATERIAL AND METHODS}

To find out the circumstances for the efficient use of a virtual laboratory, research has been made to understand the key factors.

A criterion for effectiveness of the virtual laboratory is made depending on other experiences over the past ten years.

Mostly through literature studies and depending on experience, all the assumptions are justified.

\section{RESULTS}

What people mean by a virtual laboratory, to understand what value it can bring, and importantly what it cannot and must not do. A virtual laboratory must bring as close a connection to reality as possible, to as many students as possible.

The key areas of benefit are accessibility, training and augmentation.

Nothing can replace the experience of working hands-on with laboratory equipment, the virtual laboratory should not be used to provide a full experience.

In some cases, learning a new environment or software for simulations can be difficult and time consuming.

In the context of geographical location or mobility issues, the use of a virtual laboratory may provide a substitution for a real experiment. A substitution is also necessary due to lack of equipment.

\section{DISCUSSION}

In recent years, researchers do not try to prove that virtual experiments are better than experiments in real life because such researches were made and the results in most cases do not prove that virtual experiments bring better results in students' exams.

Different researchers try to prove that using virtual environment in some cases changes the attitude towards physics and science.

In future authors will make and use virtual laboratory not only as computer simulations but also as a whole environment for learning and teaching physics and science.

\section{CONCLUSION}

The results are theoretical. However, this research is significant for future work because it helps to prevent failures and focus on things that have not been done before.

There exist some limitations due to a lack of students. Therefore, the authors can also focus on different stages of education.

\section{KEY WORDS}

Virtual laboratory, simulations, laboratory equipment 